\title{
Olfactory host location in beetle bruchid parasitoid Dinarmus basalis (Hymenoptera : Pteromalidae)
}

\author{
Oumarou RABI ${ }^{1 *}$, Ali D. BOULI ${ }^{1}$ and Jean Paul MONGE ${ }^{2}$ \\ ${ }^{I}$ Département de Biologie, Faculté des Sciences, Université Abdou Moumouni. BP 10662 Niamey, Niger. \\ ${ }^{2}$ Institut de Recherche sur la Biologie de l'Insecte URA CNRS 1298, Avenue Monge, Parc Grandmont, 37200 \\ Tours, France. \\ *Auteur correspondant, E-mail : fatimata_azzahra@yahoo.fr
}

\begin{abstract}
The role of chemicals cues in host location by the parasitoid Dinarmus basalis (Rond.) was investigated in bioassays by measuring response to stimuli associated with one of its hosts, the larvae of beetle bruchid, Bruchidius atrolineatus (Pic.) infesting Vigna unguiculata (L. Walp.) seeds. Orientation of parasitoid females was measured in response to stimuli from non host-plants: (Pennisetum typhoides (Burm.) and Sorghum bicolor (L. Moench), host-plant (cowpea) and plant-host complex. The results showed that D. basalis females were not attracted by stimuli from non host-plant but they were significantly oriented towards stimuli emanating from young host plant of $V$. unguiculata in vegetative stage and host-plant complex. Infested pods were more attractive than the healthy pods.

(C) 2010 International Formulae Group. All rights reserved.
\end{abstract}

Keywords: Bruchidius atrolineatus, chemicals cues, Vigna unguiculata.

\section{INTRODUCTION}

In West Africa, bruchid beetles are the main pest of cowpea seeds (Vigna unguiculata) which is a major source of protein in this area. Adults of two species, Bruchidius atrolineatus and Callosobruchus maculatus (F.), colonize cowpea fields at the beginning of flowering. Females of the first generation lay their eggs on green pods and later on dry pods (Alzouma and Huignard, 1981). The larvae develop inside the seeds consuming the reserves of the cotyledons. After harvesting, several generations develop on crops accounting serious losses (Monge and Huignard, 1991). The traditional methods used by farmers to protect cowpea seeds (sluggish substances, insecticidal plants and insectifuges) are less effective. Synthetic insecticides are too costly for majority of the producers. Besides these substances have consequences on the environment by toxicity in trophic chain and thus on human health (Guitart et al., 2010; Schecter et al., 2010) and by surface and subterranean water pollution (Hela et al., 2005, Andrade and Stigter, 2009).

Besides, it is necessary to mention the resistance acquired by the devastating insects due to the inconvenient and irrational use of chemical pesticides (Puinean et al., 2010). 
Biological control of cowpea pests using Hymenopteran parasitoids is an alternative currently under consideration for the protection of cowpea. Insect population dynamic studies in cowpea fields and stores identified four species of parasitoids. Three are larval species: Dinarmus basalis (Rond.) (Pteromalidae), Eupelmus vuilleti (Crawford) (Eupelmidae) and Eupelmus orientalis (Crawford) (Eupelmidae) (Monge et al., 1995). The last one is an egg parasitoid Uscana lariophaga Steffan (Trichogrammatidae) (Huis et al., 1990). However, under natural infestation conditions of cowpea seeds in the field, the number of these natural enemies is too low to provide effective control of bruchids populations. Biological control of bruchids by augmentative releases of natural parasitoids could represent an interesting alternative for the low-income small-scale producers in West Africa (Huis, 1991). The development of biological control methods particularly in fields requires knowledge on parasitoids long distance host location ability. There were several studies on this aspect to numerous species of parasitoids (Mehrnejad and Copland, 2006; Rousse et al., 2007). However there is not enough information about the question on $D$. basalis. The relations between this parasitoid and host plant are indeed poorly known. For this purpose, we investigate in this communication olfactory orientation of the parasitoid $D$. basalis.

\section{MATERIALS AND METHODS}

Plant

Individual potted plants of cowpea (cv. Black Eyes) grown on peat were maintained under greenhouse conditions $\left(32: 25{ }^{\circ} \mathrm{C} 12: 12\right.$ h ; 12: $12 \mathrm{~h} \mathrm{LD} \mathrm{;} \mathrm{70 \%} \mathrm{RH).} \mathrm{Three} \mathrm{to} \mathrm{four}$ weeks old plants of $10-15 \mathrm{~cm}$ height were used for experiments. Four plants per experiment were used.

\section{Insects}

\section{Rearing conditions}

Insects were reared under climatic conditions close to their zone of origin; $32: 25^{\circ} \mathrm{C}, 12: 12$ h; 12: 12 h L: D; 70\% RH in Niamey region in Niger.

\section{Bruchid rearing}

Thirty couples of $B$. atrolineatus were released on one hundred seeds of cowpea placed in Plexiglas box $(17.5 \times 11.5 \times 3 \mathrm{~cm})$ to facilitate oviposition. After two days, the seeds were separated from adult and progress was monitored regularly. The fourth instars larval and pupae appeared after twenty to twenty five days.

\section{Parasitoids rearing}

Newly emerged adult of $D$. basalis were placed in Plexiglas cages ( 25 x 30 x 40) with cowpea seeds containing fourth instars larvae and pupae. After two days, the seeds were removed from the cages. The adult emerges to twenty days after oviposition. They were used either for experiments or for production of new generations.

\section{General experimental conditions}

Newly emerged parasitoids were individually isolated in transparent Petri dishes $(6.5 \times 4 \mathrm{~cm})$. Insects were fed with $10 \%$ sucrose water changed daily and maintained under these breeding conditions.

\section{Olfactometric device}

The experiments were carried out in an olfactometer in form of Y-tube glass with 2.5 $\mathrm{cm}$ diameter, base length of $27 \mathrm{~cm}$ with two branches of $25 \mathrm{~cm}$ each connected to two equivalent air flows with a flow rate of 0.5 $\mathrm{m} / \mathrm{sec}$ each and meet in the common part (Figure 1). At the beginning, the flow of air is single and comes from a compressor; it passes by a filter and is then divided into two equivalent flows towards two boxes before entering in the olfactometer. One of the boxes was empty and the other contains the source of odour where the choice of the females between the fresh air and an odour was 
analyzed. In the event of test of choice between two odours, the two boxes contain each one the odourous material. For each experiment, the behaviour of thirty females was analyzed. Each female was placed at the end of the common part of the tube and was observed during three minutes. Female made a choice before three minutes and exceeded the intersection of the two branches of the olfactometer, entered and remained in one of the branches. Females which presented other behaviour were not taken into account for analysis.

\section{Odours tested}

The following materials were tested: (i) three week old cowpea plant; (ii) Fresh cowpea flowers; (iii) twenty green cowpea pods, (iv) twenty dry cowpea pods, (v) one hundred dry cowpea seeds (vi) one hundred infested dry cowpea seeds; (vii) twenty infested cowpea dry pods; (viii) three hundred g sorghum (Sorghum bicolor) dry grains and (ix) three hundred $\mathrm{g}$ millet (Pennisetum typhoides) dry grains.

Sorghum and millet are not host plants of bruchid, but were used because they are often cultivated in association with cowpea; so this parasitoid is submitted in the closely environment of its hosts and plant hosts to effluvia from both sorghum and millet.

\section{Data analysis}

The results were analysed statistically using $\chi^{2}$ square test.

\section{RESULTS}

Results on the response of Dinarmus. basalis to various sources of odour in a Ytube olfacometer are presented in Figures 2 to 4.

\section{Female response to healthy plant odours}

Dinarmus basalis females were significantly attracted by chemicals released by $V$. unguiculata young plants during vegetative stage (Figure 2). Indeed on 24 responding females, 21 have chosen the odour from the young plants $(21 / 24)\left(\chi^{2}=12\right.$; $\mathrm{P}<$ $0.01)$. A similar response was observed with flowers $(24 / 30)\left(\chi^{2}=9.6 ; \mathrm{P}<0.01\right)$ and green pods $(23 / 28)\left(\chi^{2}=10 ; \mathrm{P}<0.01\right)$.

By contrast, there were significant differences between the numbers of females entering each of the two olfactometer arms when they were exposed to effluvia from both healthy seeds $(26 / 30)\left(\chi^{2}=17.6 ; \mathrm{P}<10^{-5}\right)$ and pods $(27 / 30)\left(\chi^{2}=14.7 ; \mathrm{P}<0.001\right)($ Figure 2$)$.

\section{Female response to infested plant odours}

Regarding the infested dry seeds and pods, D. basalis females were significantly attracted by effluvia from $V$. unguiculata infested dry pods $(24 / 30)\left(\chi^{2}=14.8 ; \mathrm{P}<\right.$ $0,001)$ and seeds $(29 / 30)\left(\chi^{2}=24.3 ; \mathrm{P}<10^{-7}\right)$ (Figure 3), however, they preferentially chose the infested pods effluvia $\left(\chi^{2}=24.3 ; \mathrm{P}<10^{-7}\right)$ as compared to those from healthy pods (29/30).

\section{Female response to non host plants}

The response of $D$. basalis females to chemicals from non-host, namely millet and sorghum, did not show any a significant difference in attraction (Figure 4). The number of females attracted by the clean air tend to be higher that the one associated with females attracted by chemicals from both millet $(13 / 30)\left(\chi^{2}=0.3 ; \mathrm{P}>0.58\right)$ and sorghum $(11 / 30)\left(\chi^{2}=1.63 ; \mathrm{P}>0.2\right)$.

\section{DISCUSSION}

Our results indicate that the females of D. basalis were attracted by entire cowpea components and by the effluvia from the inflorescences. Green pods as well as the dry ones elicit a significant response of $D$. basalis female. A similar result has been found in Eupelmus orientalis (Crawford) worldwide parasitoid of Bruchidae and sympatric of $D$. basalis (Oumarou, 1999). Infochemicals associated with host habitat, are clearly 


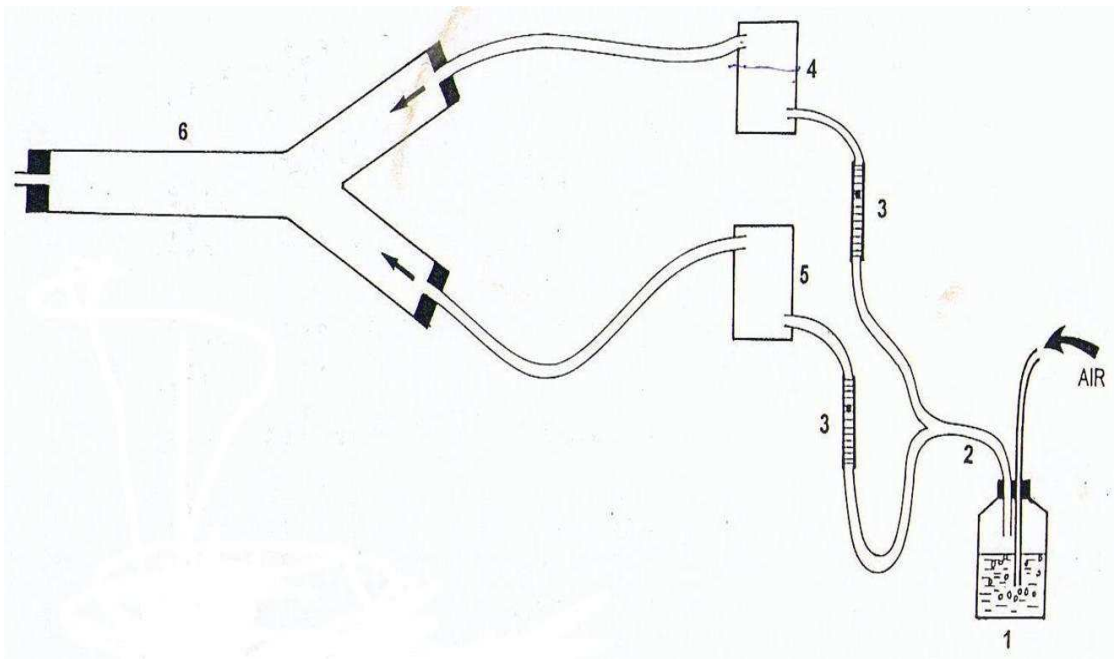

Figure 1: Olfactometric device.

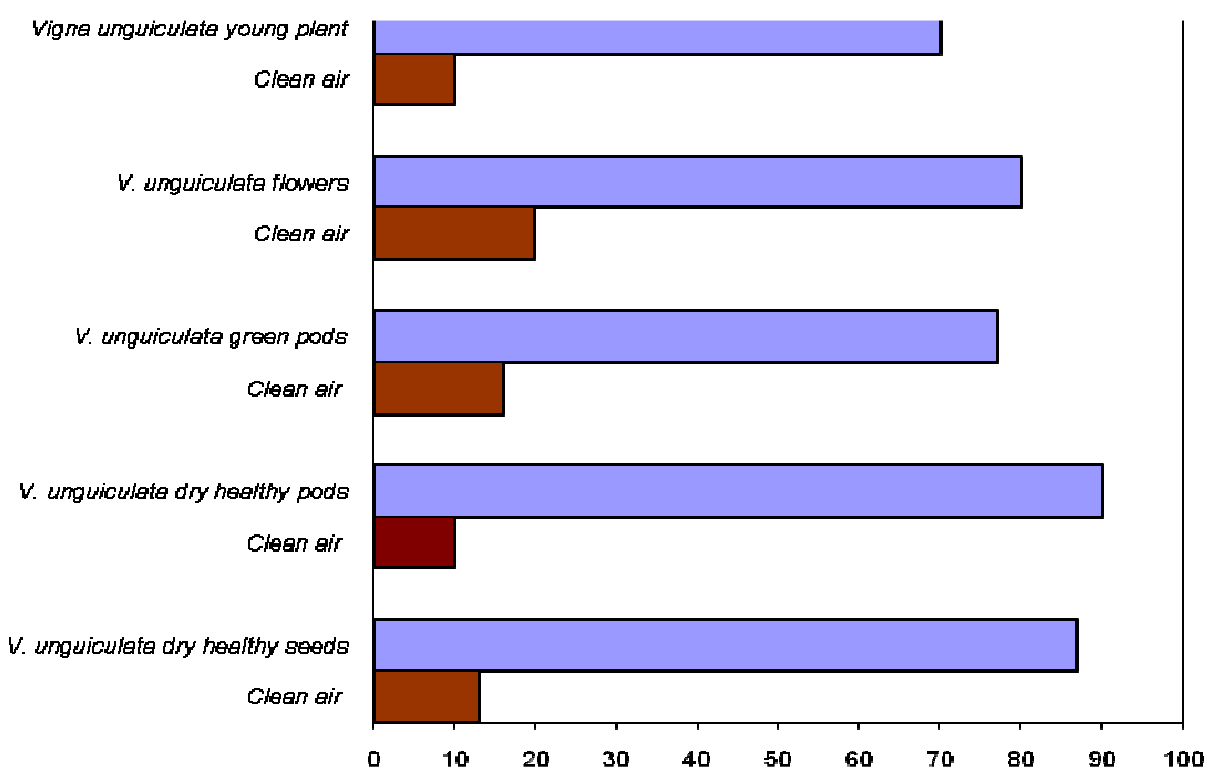

Figure 2: Response of $D$. basalis females to odours from various developmental cycle components of Vigna in a Y-tube olfacometer experiment. 


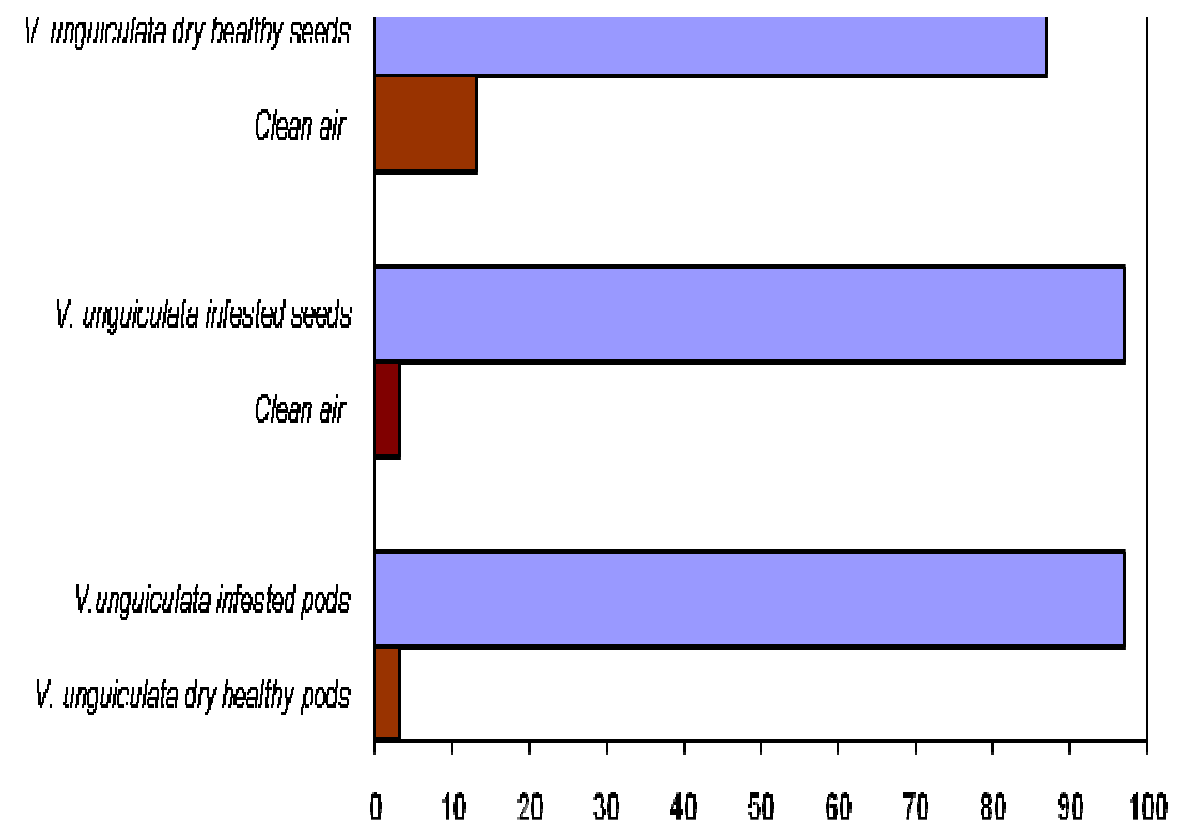

Figure 3: Response of $D$. basalis females to odours from healthy and infested pods and seeds in a Y-tube olfacometer experiment.

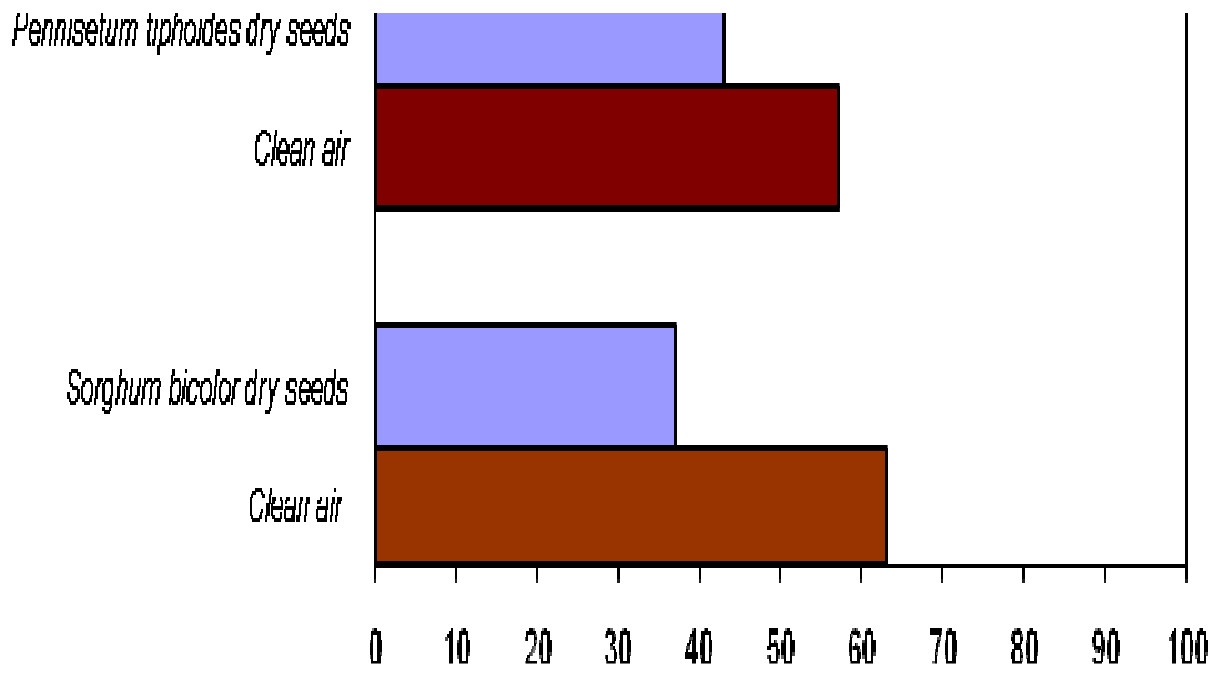

Figure 4: Response of D. basalis females to odours from non host sources in a Y-tube olfacometer experiment. 
involved in the host location in D. basalis. This was also reported in almost all species of parasitoids (Altuzar et al., 2004; Mehrnejad \& Copland, 2006; Rousse et al., 2007).

Dinarmus basalis female's attractiveness to chemicals cues emanating from all the parts of $V$. unguiculata (pods and seeds that allow host development; flowers and vegetative apparatus which do not permit such development) can be explained by nutritional factors. Indeed, the majority of adult's parasitoid are phytophagous and use for their food trophic resources available to plants level such as, extra floral and floral nectar and/or pollen (Wäckers, 2004, 2005). D. basalis females would couple olfactive emanations resulting from the young seedling, flowers and green pods of cowpea to nutritional factors. This behavior allowed them to be present in cowpea fields, before the availability of infested pods.

Dinarmus basalis females were not attracted by odours emanating from $P$. tiphoides and S. bicolor. These non host plants are often cultivated in association with $V$. unguiculata and are annual plants like $V$. unguiculata. So this parasitoid is submitted in the closely environment of its hosts and hosts plant to effluvia from $S$. bicolor and $P$. tiphoides. This result shows the specificity of infochemicals that $D$. basalis females use to recognize their host plant.

The females of $D$. basalis were attracted by infested pods and seeds as reported in many studies (Lo pinto et al., 2004; Girling et al., 2006; Mehrnejad and Copland, 2006; Rousse et al., 2007; Wyckhuys and Heimpel, 2007).

Otherwise, according to the choice between the odour resulting of the healthy pods and from the olfactive emanation infested pods, females were significantly directed towards the infested pods. Such results were reported by other authors (Hemachandra et al., 2007; Chiu-Alvarado et al., 2009). The value of chemical information for a parasitoid was depended on the degree of indication which was given on the presence of the host at an adaptive point of view (Dicke 1999). Emanations from infested seeds and pods are more reliable to host presence than those from healthy one.

These results showed that the females of $D$. basalis have a good orientation capacity towards the odours emanating from various parts and entire healthy plants. In addition, it discriminates very well between infested pods and the healthy pods.

\section{ACKNOWLEDGMENTS}

We thank Dr Zaman-Allah Mainassara and Sanjeet Kumar for productive discussions and for improving the English version of the manuscript.

\section{REFERENCES}

Altuzar A, Montoya P, Rojas J. 2004. Response of Fopius arisanus (Hym: Braconidae) to fruit volatiles in a wind tunnel. Florida Entomologist, 87: 616618.

Alzouma I, Huignard J. 1981. Données préliminaires sur la biologie et le comportement de ponte de Bruchidius atrolineatus (Pic.) (Coleoptera : Bruchidae) dans une zone sud sahélienne au Niger. Acta Oecologia, 2(4): 391-400.

Alzouma I. 1987. Reproduction et développement de Bruchidus atrolineatus (Pic) aux dépens des cultures de Vigna unguiculata (Walp.) dans un agrosystème sahélien au Niger. Thèse, Université de Tours, p.162.

Andrade A, Stigter TY. 2009. Multi-method assessment of nitrate and pesticide contamination in shallow alluvial groundwater as a function of hydrogeological setting and land use. Agricultural Water Management, 96(12): 1751-1765.

Chiu-Alvarado P, Barrera JF, Rojas JC. 2009. Attraction of Prorops Nasuta (Hymenoptera: Bethylidae), a parasitoid 
of the coffee berry borer (Coleoptera: Curculionidae), to host-associated olfactory cues. Annals of the Entomological Society of America, 102(1):166-171.

Dicke M. 1999. Evolution of induced indirect defense of plants. In The Ecology and Evolution of Inducible Defenses. Tollrian R, Harvell CD (eds). Princeton University Press: Princeton, USA; 62-88.

Girling RD, Hassall M, Turner JG, Poppy GM. 2006. Behavioural responses of the aphid parasitoid Diaeretiella rapae to volatiles from Arabidopsis thaliana induced by Myzus persicae. Entomologia Experimentalis et Applicata, 120: 1-9.

Guitart R, Sachana M, Caloni F, Croubels S, Vandenbroucke V, Berny P. 2010. Animal poisoning in Europe. Part 3: Wildlife. Veterinary Journal, 183(3):260265.

Hela DG, Lambropoulou DA, Konstantinou IK, Albanis TA. 2005. Environmental monitoring and ecological risk assessment for pesticide contamination and effects in Lake Pamvotis, north western Greece. Environmental Toxicology and Chemistry, 24(6): 1548556.

Hemachandra KS, Kuhlman, U, Mason PG, Holliday NJ. 2007. Spatial patterns of Trybliographa rapae parasitism of Delia radicum larvae in oilseed rape and cauliflower. Journal of Applied Entomology, 131: 338-246

Huis van A. 1991. Biological methods in bruchid control in the tropics: a review. Insect Science and its Application, 12:87102.

Huis_van A, Kaashoek NK, Lammers PM. 1990. Uscana lariophaga (Hymenoptera: Trichogrammatidae), egg parasitoid of two bruchid species of cowpea in West Africa. Proc Exp Appl Entomol, N.E.V. Amsterdam 1, 101106.

Lo Pinto M, Wajnberg E, Colazza S, Curty C, Fauverge X. 2004. Olfactory responses of two aphid parasitoids, Lysiphlebus testaceipes and Aphidius colemani, to aphid-infested plants from a distance. Entomologia Experimentalis et Applicata, 110: $159-164$.

Mehrnejad MR, Copland MJW. 2006. Behavioral responses of the parasitoid Psyllaephagus pistaciae (Hymenoptera: Encyrtidae) to host plant volatiles and honeydew. Entomological Science, 9: 3137.

Monge JP, Huignard J. 1991. Populations fluctuations of two Bruchid species Callosobruchus

maculatus (Fab.) and Bruchidius atrolineatus (Pic.) (Coleoptera: Bruchidae) and their parasitoids Dinarmus basalis (Rond.) and Eupelmus Vuilleti (Crwf.) (Hymenoptera: Pteromalidae, Eupelmidae) in a storage situation in Niger. Journal of African Zoology, 105: 187-196.

Monge JP, Dupont P, Idi A, Huignard J. 1995. The consequences of interspecific competition between Dinarmus basalis (Rond) (Hymenoptera: Pteromalidae) and Eupelmus vuilleti (Crw) (Hymenoptera: Eupelmidae) on the development of their host population. Acta Oecologia, 16: 1930 .

Oumarou R. 1999. Colonisation des cultures de niébé Vigna unguiculata par les Hyménoptères parasitoïdes: approche écologique et comportementale. Thèse de Doctorat $3^{\mathrm{e}}$ cycle. Université Abdou. Moumouni de Niamey, p. 137.

Puinean AM, Denholm I, Millar NS, Nauen R, Williamson MS. 2010. Characterisation of imidacloprid resistance mechanisms in the brown planthopper, Nilaparvata lugens Stål (Hemiptera: Delphacidae) Pesticide Biochemistry and Physiology, 97(2): 129132.

Rousse P, Chiroleu J, Veslo T, Quilici S. 2007. The host- and microhabitat olfactory location by Fopius arisanus 
suggests a broad potential host range. The Royal Entomological Society, Physiological Entomology, 32: 313-321.

Schecter A, Colacino J, Haffner D, Patel K, Opel M, Päpke O, Birnbaum L. 2010. Perfluorinated compounds, polychlorinated biphenyls, and organochlorine pesticide contamination in composite food samples from Dallas, Texas, USA. Environmental Health Perspectives, 118: 796-802.

Wäckers FL. 2004. Assessing the suitability of flowering herbs as parasitoid food sources: flower attractiveness and nectar accessibility. Biological Control, 29: $307-$ 314

Wäckers FL. 2005. Suitability of (extra-) floral nectar, pollen and honeydew as insect food sources. In Plant-Provided Food for Carnivorous Insects, Wäckers FL, Van Rijn PCJ, Bruin J (eds). Camebridge University Press; 17-74.

Wyckhuys KAG, Heimpel GE. 2007. Response of the soybean aphid parasitoid Binodoxys communis to olfactory cues from target and non-target host-plant complexes. Entomologia Experimentalis et Applicata, 123(2): 149-158. 